\title{
MULTI AREA FREQUENCY AND POWER RESPONSE OF HYBRID POWER SYSTEM
}

\author{
Rajkumar M \\ PG Scholar[PSE],Dept of EEE, Adhiyamaan College of Engineering, Hosur, Tamilnadu, \\ India. \\ Prof.J.Jalendiran \\ Assistant Professor, Dept of EEE, Adhiyamaan College of Engineering, Hosur, Tamilnadu, \\ India
}

\begin{abstract}
This paper proposes the implementation of intelligent control technique to design standalone controllers based on Adaptive Neuro Fuzzy inference System (ANFIS) for Load Frequency Control (LFC). The proposed controllers are developed with aim to minimize frequency deviation while reducing transient state time which are integrated in three area interconnected hybrid power system entailing hydro, solar and wind power generating units. The comparative analysis between the two controllers shows that ANFIS based controller performing better than FL based controller. This type of LFC technique guarantees the steady state system stability which can be verified with the simulation result.
\end{abstract}

Keywords: Load Frequency Control(LFC), Automatic Generation Control(AGC), Neural Network, Fuzzy Logic, Intelligent Control

Cite this Article: Rajkumar M and Prof.J.Jalendiran, Multi Area Frequency and Power Response of Hybrid Power System, International Journal of Electrical Engineering \& Technology, 10(1), 2019, pp. 52-59.

http://iaeme.com/Home/issue/IJEET?Volume $=10 \&$ Issue $=1$

\section{INTRODUCTION}

Load Frequency Control (LFC) is integral part of Automatic Generation Control (AGC) system serving the objective of regulating the frequency to desired level which ensures the quality and reliability of overall power system. Over the past few decades several techniques has been proposed for LFC. The most common methodology which is widely adopted around globe since the beginning of time is fixed gain based Proportional Integral (PI) controllers, but with exponentially growing electricity market necessity for more progressive control techniques arises for proper functioning of large number of interconnected generating units. LFC is formulated with aim to satisfy the balance between load power demand and supply, and in addition to maintain tie line power flow and steady state frequency to nominal value under the load disturbances. Power generating area are highly non-linear system which are very difficult to cope up with, which increases as the number of interconnected power system increases. 
An iterative linear approximation based matrix algorithm is formulated to linearize the system. Modern control procedure based on Artificial Neural Network (ANN), genetic algorithm crafted network and Fuzzy Logic based Controller (FLC) are assessed for LFC problem. application of shared technique of FLC and ANN is also being studied. Also the genetic algorithm based Bayesian network control strategy for LFC which is more flexible in outlining control objectives including probabilistic local varying condition gives new evidence in support and need of intelligent control. PID gains for three area interconnected system is also enhanced using evolution algorithm for single input FPID controller. Though plentiful effort have been made for optimizing conventional LFC but very fewer effort in designing robust intelligent controller for hybrid generating units. Fuzzy control applied in power system tested for dynamic performance for different number of input membership functions. This paper intends to designing of two different controller falls in identical category one of them is centred on fuzzy logic approach with variable structure fuzzy data providing optimum control over fluctuating non-linear operating condition, other one is developed with the support of Artificial Neural Network built on back prorogation algorithm which is trained to acclimatize the nonlinear control environment and provide satisfactory appreciation over frequency variations and tie line power flow.

\section{DYNAMIC SYSTEM MODEL OF MULTI AREA LFC}

System under investigation consist of three area interconnected power system with one area including hydro power generating units, second area will have solar power generating units and third area includes wind generating power units. The basic difference between three areas is in terms of settling time in which case the later one is most laggard. Transfer function model block diagram for three area system under deliberation is shown in Fig. 1. It is certain that LFC has two control loops one act for primary control to topple small deviation that occurred with in the area, while the secondary control loop gets activated only after primary controller has acted. The projected controllers are examined in secondary control loop for intra area deviation in frequency and tie-line power. Basic functioning of LFC is to normalize the Area Control Error (ACE), which by definition is summation of errors triggered by frequency deviation $\Delta \mathrm{f}_{\mathrm{n}}$ and tie-line power flow. For $\mathrm{n}^{\text {th }}$ area ACE is given

$$
\mathrm{ACE}_{(\mathrm{n})}=\Delta \mathrm{P}_{\mathrm{TLn}}(\mathrm{s})+\mathrm{B} \Delta \mathrm{f}_{\mathrm{n}}(\mathrm{s})
$$

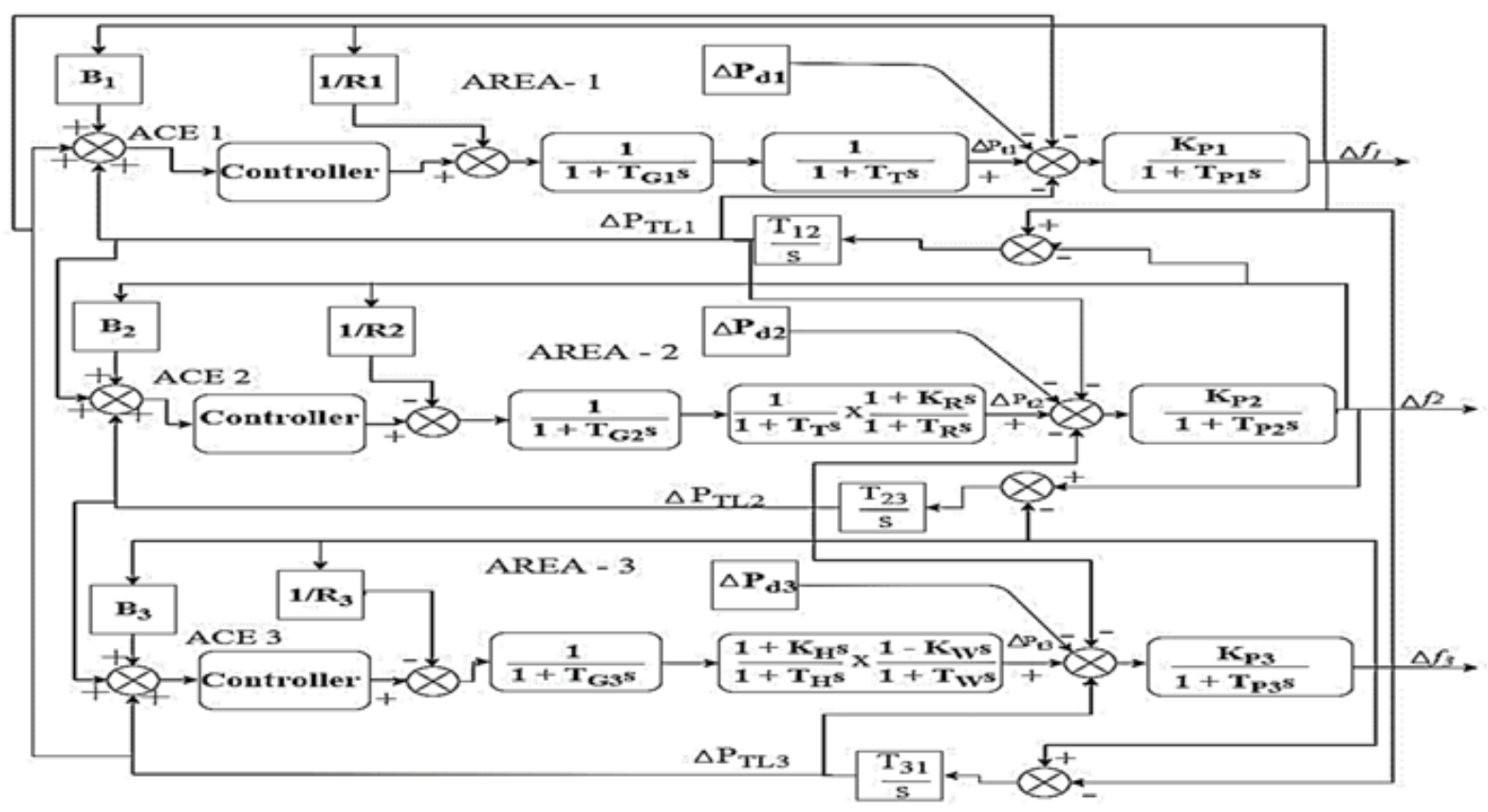


Figure 1 Transfer Function Block Representation of Three area LFC

\section{CONTROLLER DESIGN METHODOLOGY}

\subsection{Adaptive Neuro-Fuzzy Inference System}

An Adaptive Neuro-Fuzzy Inference System or adaptive network-based fuzzy inference system (ANFIS) is a kind of artificial neural network that is based on Takagi-Sugeno fuzzy inference system. The technique was developed in the early 1990s. Since it integrates both neural networks and fuzzy logic principles, it has potential to capture the benefits of both in a single framework. Its inference system corresponds to a set of fuzzy IF-THEN rules that have learning capability to approximate nonlinear functions. Hence, ANFIS is considered to be a universal estimator. For using the ANFIS in a more efficient and optimal way, one can use the best parameters obtained by genetic algorithm. A FIS was built on the three main components, namely basic rules, where it consists of the selection of fuzzy logic rules "If-Then;" as a function of the fuzzy set membership; and reasoning fuzzy inference techniques from basic rules to get the output. Figure shows the detailed structure of the FIS.

FIS will work when the input that contains the actual value is converted into fuzzy values using the fuzzification process through its membership function, where the fuzzy value has a range between 0 and 1 . The basic rules and databases are referred to as the knowledge base, where both are key elements in decision-making. Normally, the database contains definitions such as information on fuzzy sets parameter with a function that has been defined for every existing linguistic variable. The development of a database typically includes defining a universe, determination of the number of linguistic values to be used for each linguistic variable, as well as establish a membership function. Based on the rules, it contains fuzzy logic operators and a conditional statement "If-Then." The basic rules can be constructed either from a human or automatic generation, where the searching rules using input-output data numerically. There are several types of FIS, namely Takagi-Sugeno, Mamdani, and Tsukamoto (Cheng et al. 2005). A FIS of Takagi-Sugeno model was found to be widely used in the application of ANFIS method.

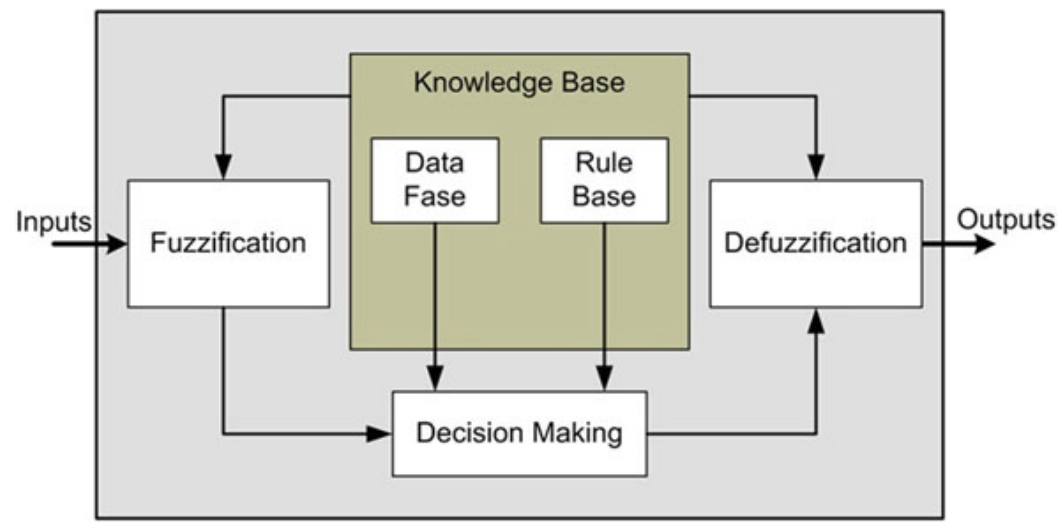

Figure 2 Fuzzy Inference System

\subsection{Adaptive Network}

Adaptive network is one example of feed forward neural network with multiple layers. In the learning process, these networks often use supervised learning algorithm. In addition, adaptive network has the architecture characteristics that consists of a number of adaptive nodes interconnected directly without any weight value between them. Each node in this network has different functions and tasks, and the output depends on the incoming signals and parameters that are available in the node. A learning rule that was used can affect the parameters in the 
node and it can reduce the occurrence of errors at the output of the adaptive network. In learning the basic adaptive network, it is normally using gradient descent or back propagation and the chain rule. All this learning algorithms had been proposed by Werbos in 1970 (Jang 1993). Till date, gradient descent or back propagation is still used as a learning algorithm in an adaptive network. Even so, there are still found weaknesses in the back propagation algorithm and further can reduce the capacity and accuracy of adaptive networks in making decisions. The slow convergence rate and tend to always stuck in local minima are major problems on back propagation algorithm. Therefore, Jang (1993) have proposed an alternative learning algorithm, namely hybrid learning algorithm, which has the better ability to accelerate convergence and avoid the occurrence of trapped in local minima.

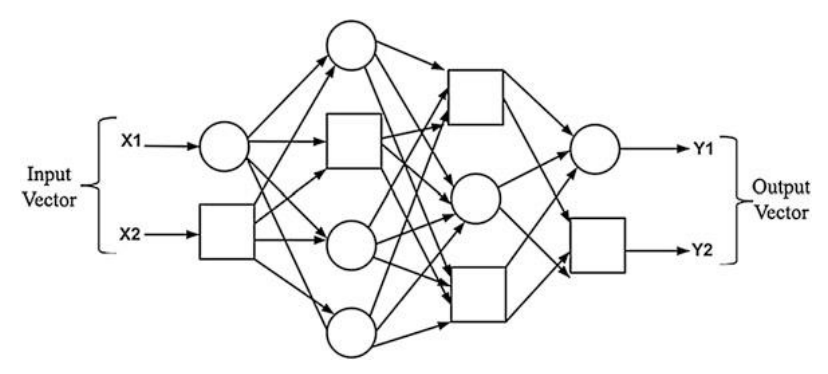

Figure 3 Artificial Neural Network

Customized neural network is created using MATLAB neural network tool with activation function TRAINGDX having learning function LEARNGDM and the transfer function used is LOGSIG. The created network is trained using 1 epoch until regression value for training data reaches very close to 1 .

\section{SIMULATION AND RESULT ANALYSIS}

Simulation of both controller is carried out on same three area closed loop system shown in Fig. 1 having GRC unchanged with uneven loading for $1 \%$ step load change induced at 1 sec keeping all other variable constant. The three area system parameters are given in Appendix. The frequency deviation for ANN and FLC for three area is depicted in Fig. 4 and Fig. 5 respectively. It is determined that the average settling time is around hundred seconds.

\subsection{Controller Fuzzy Rule}

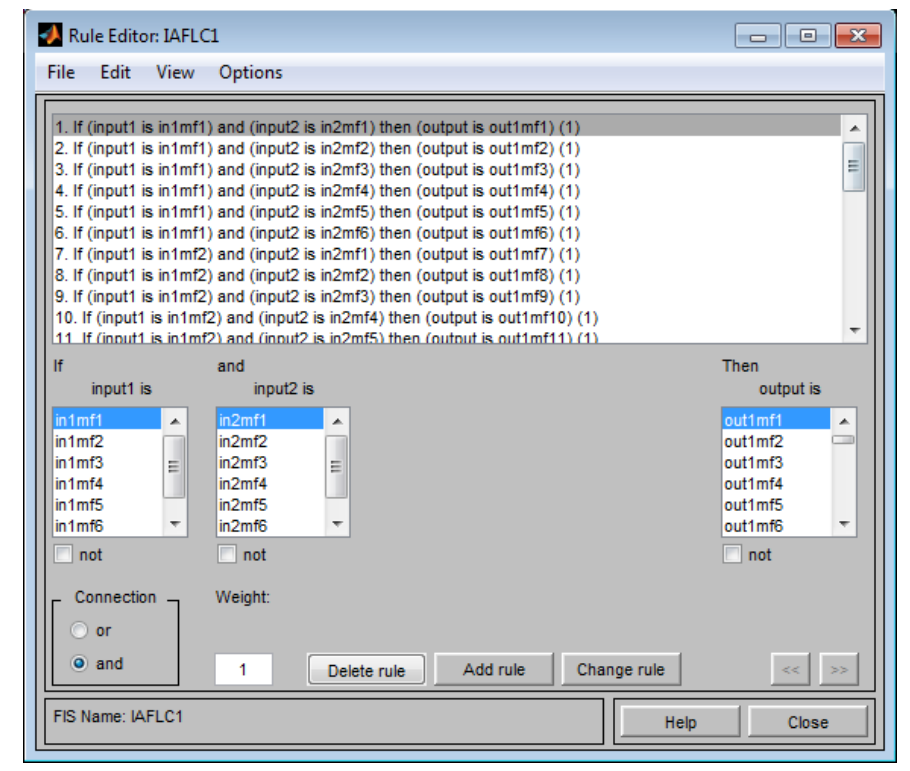


Rajkumar M and Prof.J.Jalendiran

Figure 4 Controller Fuzzy Rule

\subsection{Controller Function Plots}

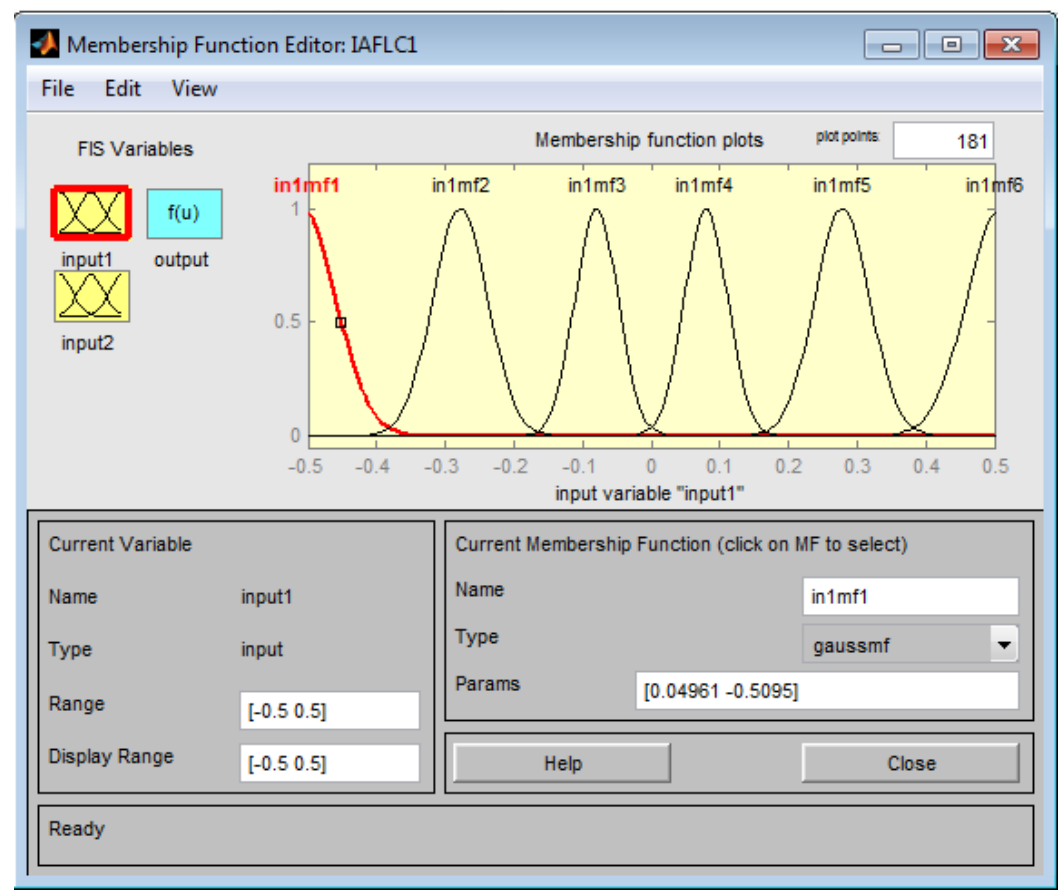

Figure 5 Controller Function Plots

\subsubsection{Output voltage for frequency deviation 1}

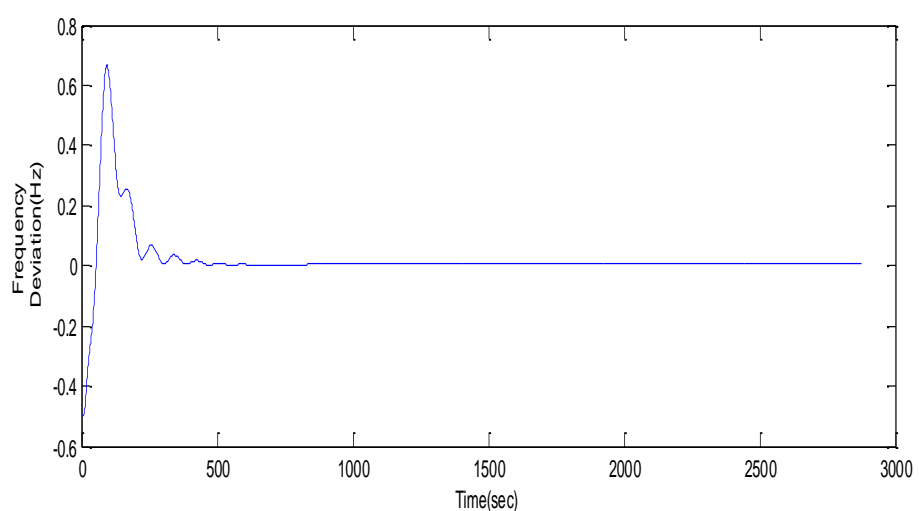

Figure 6 Output voltage for frequency deviation1

\subsubsection{Output power deviation between Frequency deviation1 \& Frequency deviation2}


Multi Area Frequency and Power Response of Hybrid Power System

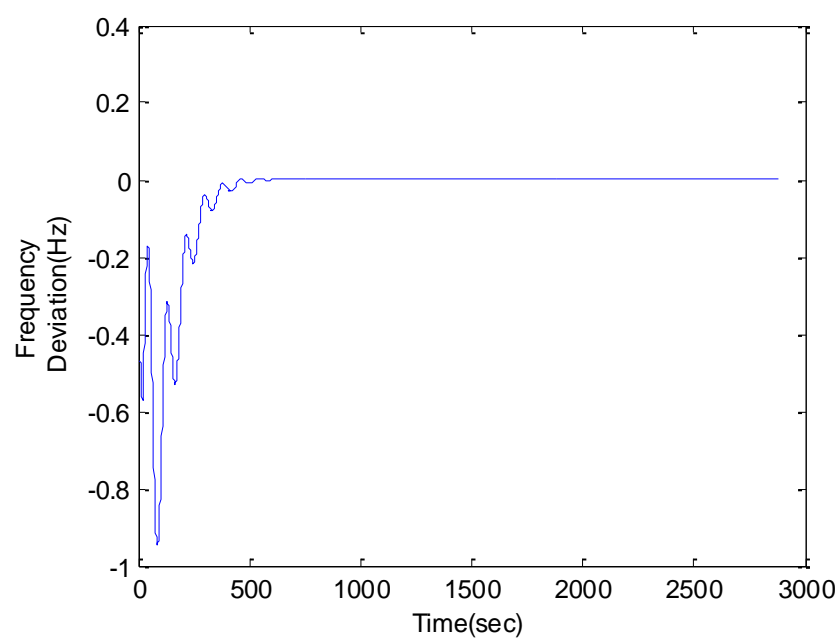

Figure 7 Output power deviation between Frequency deviation 1 \& Frequency deviation2

\subsubsection{Output voltage for frequency deviation2}

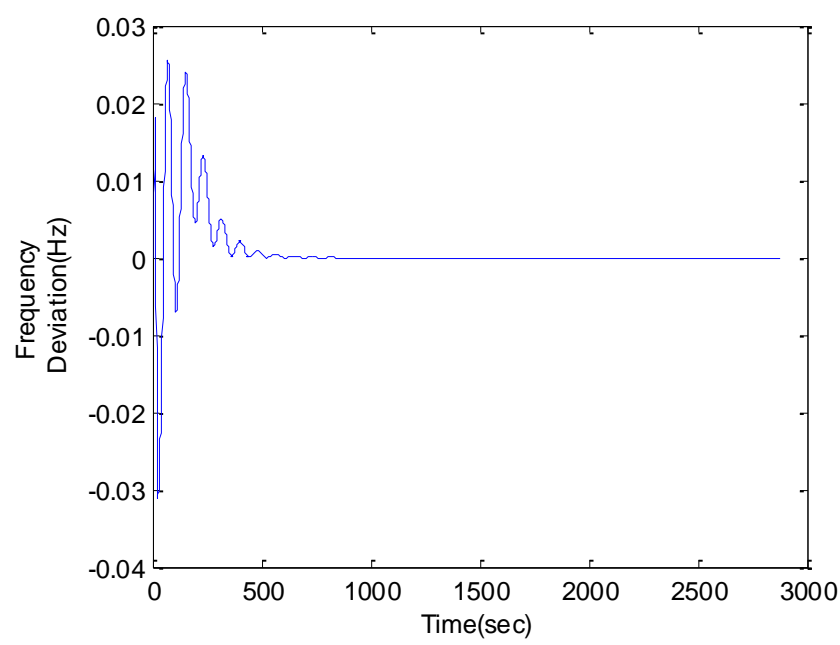

Figure 8 Output voltage for frequency deviation2

\subsubsection{Output voltage for frequency deviation3}

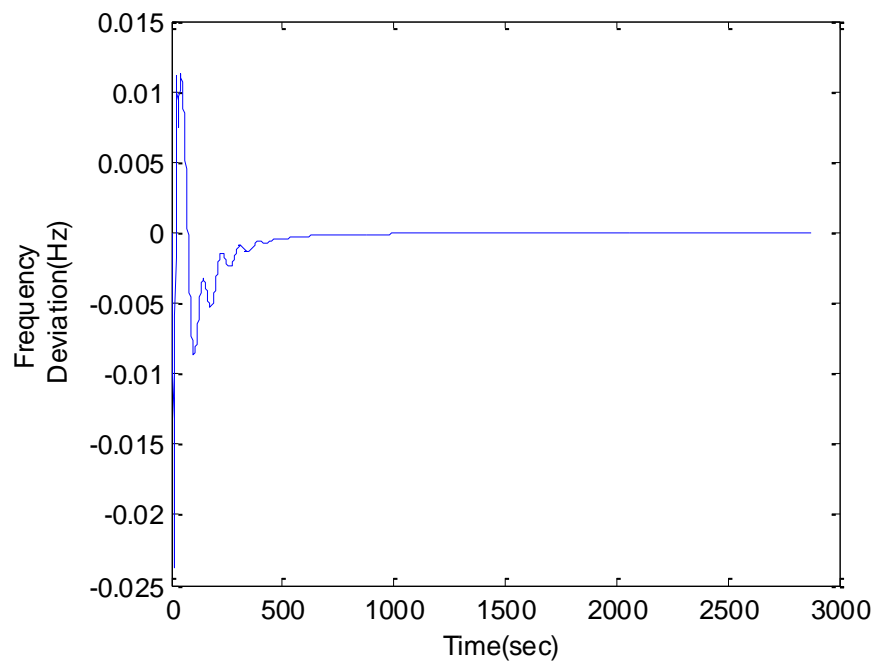


Figure 9 Output voltage for frequency deviation3

\subsubsection{Output power deviation between Frequency deviation2 \& Frequency deviation3}

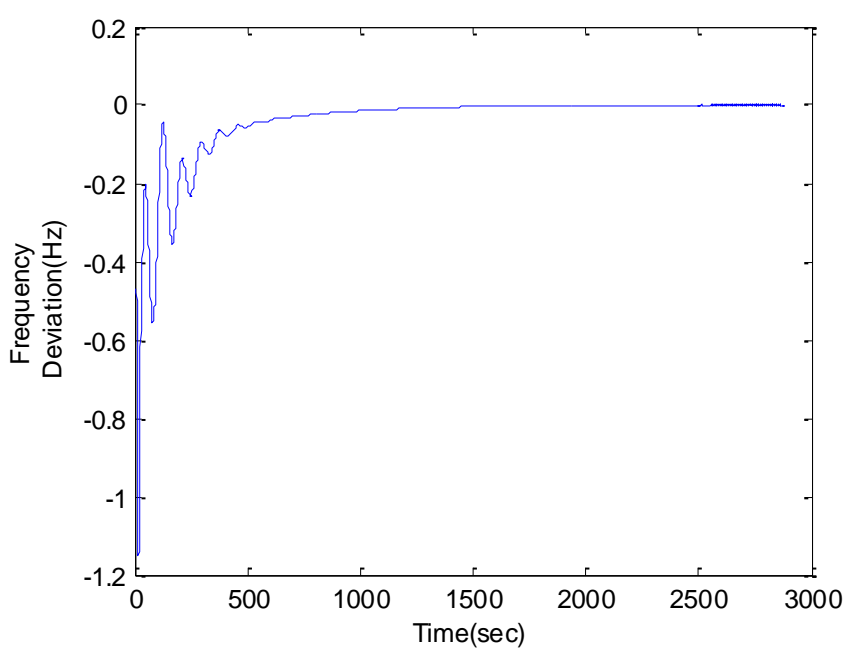

Figure 10 Output power deviation between Frequency deviation2 \& Frequency deviation3

\section{CONCLUSION}

The fundamental analysis between the two most debated intelligent adaptive control technique that are used to implement the LFC interconnected hybrid system by Adaptive Neuro-Fuzzy interference (ANFIS) based Controllers. Designed controllers are incorporated in three area hybrid power system with the different loading in each area and controllers achieved the primary commitment of keeping the steady state error to zero. Adaptive property of the controller benefits the overall system to alleviate quickly even with the highly nonlinear operating condition. The response period for both the controller is instantaneous because of the memory based learning process. ANFIS based controller is proved to be more effective than FL controller because of the more advanced learning process that it embraces. The various comparative simulation results between two controllers evidently show that the ANFIS controller is quicker and have less troughs and peaks during the transient time. The ANFIS based technique is providing more promising results which can be extended to distributed generation system, for large number of inter connected system for load frequency control practices.

\section{REFERENCES}

[1] P. Kundur, Power System Stability and Control, Mc-Graw Hill, 2007.

[2] H. Shayeghi, H.A. Shayanfar, and A. Jalili, "Load frequency control strategies: A state-ofthe-art survey for the researcher", Energy Conversion and Management, pp. 344-353, 2009.

[3] Dola Gobinda Padhan and Somanath Majhi, "A new control scheme for PID load frequency controller of single-area and multi-area power systems" ISA Transactions, pp. 242$251,2013$.

[4] H. Bevrani, P. R. Daneshmand, "Fuzzy Logic-Based Load- Frequency Control Concerning High Penetration of Wind Turbines", IEEE Systems Journal, pp. 173-180,April 2012.

[5] H. Bevrani, Y. Mitani, and K. Tsuji, "Robust decentralized load frequency control using an iterative linear matrix inequalities algorithm", Proc. Inst. Electr. Eng. Gener. Transm. Distrib.,vol.151, no.3, May 2004.

[6] [6] X. J. Liu and J. W. Zhang, "CPS compliant fuzzy neural network load frequency control”, American Control Conference, St. Louis, pp. 2755-2760,June 2009. 


\section{Multi Area Frequency and Power Response of Hybrid Power System}

[7] S. Zhang, Y. Mishra, and M. Shahidehpour, "Fuzzy-logic based frequency controller for wind farms augmented with energy storage systems," IEEE Trans. Power Syst., vol. 31, no. 2, pp.1595-1603, March 2016.

[8] M. Datta, T. Senjyu, A. Yona and T. Funabashi, "Fuzzy control of MW-class PV generation to reduce frequency and tie-line power fluctuations in three control area power system," 2011 IEEE International Conference on Fuzzy Systems, Taipei, pp. 2440-2447,2011.

[9] F. Daneshfar, and H. Bevrani, "Load-Frequency Control: A GA based Multi-agent Reinforcement Learning”, IET Generation, Transmission \& Distribution, vol. 4, no. 1, pp. 13-26, 2010.

[10] Djukanovic M.B., Dobrijevic D.M., Calovic M.S., Novicevic M., Sobajic D.J., "Coordinated stabilizing control for the exciter and governor loops using fuzzy set theory and neural nets", Electrical Power and Energy Systems, pp. 489-499,1997.

[11] F. Daneshfar, H. Bevrani and F. Mansoori, Bayesian networks design of load-frequency control based on GA", The $2^{\text {nd }}$ International Conference on Control, Instrumentation and Automation, Shiraz, pp. 315-319, 2011.

[12] T. K. Pati, J. R. Nayak, B. K. Sahu and B. Gantayat, "Load frequency control of an interconnected three-area thermal power system using conventional PID \& Fuzzy-logic controller," 2015 International Conference on Energy, Power and Environment: Towards Sustainable Growth (ICEPE), Shillong, , pp. 1-6,2015.

[13] H. N. Azadani and R. Torkzadeh, "Design of GA optimized fuzzy logic-based PID controller for the two area non-reheat thermal power system", 13th Iranian Conference on Fuzzy Systems (IFSC), 2013,

[14] H. A. Yousef, K. AL-Kharusi, M. H. Albadi and N. Hosseinzadeh, "Load Frequency Control of a Multi-Area Power System: An Adaptive Fuzzy Logic Approach", IEEE Transactions on Power Systems, vol. 29, no. 4, pp. 1822-1830, July 2014.

[15] R. Chaudhary, N.K. Mehta, "Load frequency control of multiarea hybrid power system using intelligent controller based on fuzzy logic", International Journal of Innovative Research in Science, Engineering \& Technology, vol. 6 issue 2, pp. 1515- 1522, February 2017.

[16] R. Chaudhary, S.K. Bhardwaj and S. Agrawal, "Automatic generation control of hybrid system using controller based on neural network", International Journal of Engineering Science Technology and Research, vol.1, issue. 5, pp. 65-74, January2017. 